Journal of

Educational Administration 38,5

468

\section{Colonial models and the evolution of education systems Centralization and decentralization in Hong Kong and Macau}

\author{
Kwok-Chun Tang \\ Hong Kong Baptist University, Kowloon, Hong Kong, and \\ Mark Bray \\ The University of Hong Kong, Hong Kong
}

Keywords Centralization, Decentralization, Politics, Hong Kong

Abstract Within the analytical framework proposed by Margaret Archer, this paper charts the emergence and development of education systems during the twentieth century in Hong Kong and Macau. Although these two territories have much in common, in education they display considerable differences. During the twentieth century the Hong Kong authorities constructed a highly centralized system, which at the end of the century moved towards decentralization. In Macau, by contrast, government neglect led to an uncoordinated collection of imported systems. At the end of the century the Macau government endeavored to unify the sector, but faced major challenges and limitations.

The study of centralization and decentralization is often assisted by comparative analysis. Comparison commonly reveals similarities, and can form a basis for enhancement of conceptual understanding. With such a goal in mind, this paper compares the evolution of education systems in a pair of territories which have much in common but which also have significant differences. Commonalities include the fact that the two territories are geographically close, are culturally related, have economic similarities, and have similar political frameworks. However, their education systems have evolved in very different ways.

The paper is contextualized in the twentieth century colonial histories of the two territories. Hong Kong was a British colony until sovereignty reverted to China in 1997, and Macau was under Portuguese administration until sovereignty reverted to China in 1999. Influences from China have been felt in each territory over the decades, though they have been complex. The resumption of Chinese sovereignty did not immediately have a major effect on the administration of education because constitutional and political arrangements allowed the authorities in both Hong Kong and Macau to continue to operate their education systems independently of each other and of the rest of China. The paper begins by outlining some key concepts from the literature which provide an analytical framework. It then presents some background information on each territory before turning to evolution in their education systems. 


\section{Theoretical models and conceptual frameworks}

The starting point for this paper is Archer's $(1984$, p. 3) work on the evolution of education systems. While many analysts now take the existence of education systems for granted, Archer pointed out that they were rare before the eighteenth century. They emerged from complex socio-cultural interactions constrained by structural and cultural forces.

Based particularly on her work in Denmark, England, France and Russia, Archer identified two cycles of evolution in education systems (Figure 1). At the beginning of the first cycle, Archer suggested, common features of education preceding the development of state systems included monointegration and subordination. Those who controlled education also owned it and monopolized the formal instruction. This feature conditioned subsequent processes of educational interaction and change. In order to challenge the dominant groups, assertive groups overcame the domination by either substitution or restriction. Substitution undermined the monopoly of dominant groups through competition building and maintaining new schools, and recruiting, training and paying new teachers. Restriction undermined the monopoly by coercive power appropriating buildings, confiscating educational funds, and excluding personnel from teaching and administration. The final phase of the first cycle dealt with educational changes resulting from the social interaction. Decentralized and centralized education systems emerged respectively from substitution and restriction. Unification and systematization were strong characteristics of the newly emerged centralized systems, with differentiation and specialization gradually accommodated to them. Newly emerged decentralized systems which had no dominant elements were characterized by specialization and differentiation, and this created obstacles to efforts at unification and systematization.

At the beginning of the second cycle, according to this analysis, the emergent centralized and decentralized systems exerted dissimilar influences on interaction. In centralized systems, professional and external interest groups

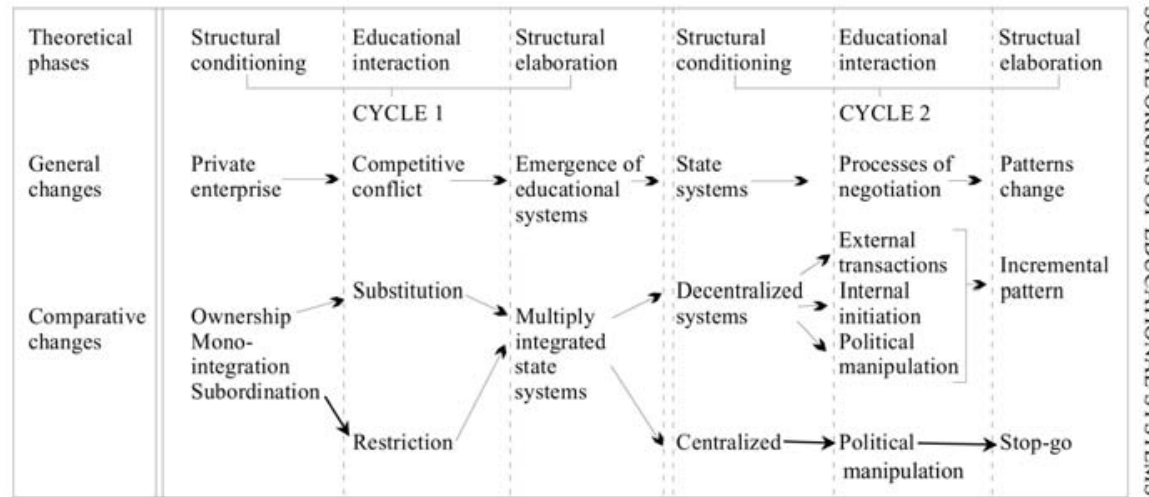

Source: Archer (1984), p.10. [Reproduced with permission from the publisher.]
Evolution of education systems

469
Figure 1. Summary diagram of Archer's study 
Journal of Educational Administration 38,5 manipulated governing elites, which then directed educational change. In decentralized systems, interest groups still manipulated governing elites, but also interacted with each other and directly influenced the nature of educational change. Archer suggested that in centralized systems, polity-directed changes which are routinely negotiated through political manipulation have similar features in terms of their initiation, legislation and execution, and have a "stopgo" pattern. Decentralized systems do not have stop-go patterns because politydirected changes are usually modified by internal initiation and external transactions which maintain a flow of small localized changes.

By the early and mid-twentieth century few countries and even colonial territories did not have distinctive education systems. One exception, as this paper will show, was Macau. The territory is idiosyncratic and small, and for these reasons has received little scholarly attention. However, the unusual features of Macau provide contrasts which cannot easily be found elsewhere, and thus form a valuable model for investigation.

Moreover, during the period covered by this paper both Macau and Hong Kong were colonies. Archer stressed (1984, p. 14) that her analysis applied only to countries in which macroscopic change emerged autonomously, and not to settings where it could be attributed to external intervention via conquest, colonization or territorial redistribution. Few scholars have endeavored to extend Archer's work to colonies; and no scholars have investigated the insights to be gained from this particular pair of colonies.

\section{An introduction to Hong Kong and Macau Hong Kong}

In a chronological sense, Hong Kong was the younger of the two colonies. However, discussion here commences with Hong Kong because it is larger, underwent post-colonial change of sovereignty slightly earlier, and in several respects set the model for Macau's colonial transition.

The territory of Hong Kong comprises the island of Hong Kong, a number of other islands, and part of the Chinese mainland. The island of Hong Kong was ceded to the British in 1842. A section of the Kowloon Peninsula was ceded in 1860; and the New Territories were acquired on a 99-year lease in 1898. The total land area is 1,070 square kilometers.

Hong Kong, like Macau, was seen primarily as a trading port rather than a territory for economic exploitation in its own right. In this respect it differed from many other British colonies. Hong Kong had a largely transient population, and most domains of social policy in the early years were low key. Nevertheless, early education policy differed from other aspects of social policy in being more active and interventionist. One aspect was in the provision of school grants, a practice which paralleled measures in Britain itself. As observed by Sweeting $(1990,1993)$, much of the history of education in Hong Kong has been a pattern of increasing government commitment and intervention. 
Although it was probably not foreseen at the time, the 99-year lease on the New Territories taken out in 1898 sowed the seeds for the colony's demise. The lease expired in 1997, when the whole of Hong Kong (i.e. including Hong Kong Island, which had been ceded "in perpetuity") was returned to China. The terms under which Chinese sovereignty resumed were established between the British and Chinese governments in 1984.

Since 1997, Hong Kong has been governed as a special administrative region (SAR) under the formula of "One country, two systems", which permits a high degree of autonomy. In particular, while the rest of China remains officially socialist, Hong Kong remains officially capitalist. The SAR system, which has been put in place for at least 50 years, also permits Hong Kong to have its own currency, laws and education system.

The population of Hong Kong is approximately 7 million. Almost 98 per cent are Chinese, for the majority of whom Cantonese is the mother tongue. Among the remainder, the largest groups are from the Philippines, Indonesia, the USA, Canada and the UK.

Particularly from the 1970s to the 1990s, Hong Kong achieved high rates of economic growth. In 1998, Hong Kong had an estimated per capita gross domestic product (GDP) of US\$24,700 (Government of Hong Kong, 1999, p. 429). Economic growth has greatly facilitated expansion of education.

\section{Macau}

As a distinct political entity, Macau is considerably older than Hong Kong, for Portuguese traders secured from the Chinese authorities rights of settlement in 1557. Although the Portuguese were primarily interested in Macau for economic reasons, the territory also played a major religious and cultural role. The church established many schools, and Macau was a conduit through which Western education and science entered China, Japan and Korea.

After the mid-seventeenth century, Macau's fortunes declined. Portugal proved unable to hold her empire together, and competition for East Asian trade became increasingly intense. The foundation of Hong Kong in 1842 was a serious blow, for its superior port took over the strategic significance that Macau had previously enjoyed. Macau became little more than an inwardlooking backwater.

After the Second World War the Chinese government wished to repossess the territory, but was unable to force the issue. For a time, policies were left at the level of official pronouncements. However, China's Cultural Revolution in 1966 led to riots in Macau and to vigorous anti-Portuguese propaganda. Unexpectedly, when the Portuguese announced that they intended to leave, the Communists altered their stance. The Chinese authorities were conscious of Macau's role as an outlet for external trade, and found it more useful to retain Macau as a foreign port than to repossess it.

Eight years later, Portugal itself experienced a revolution, and immediately set about decolonizing its African territories. However, the Chinese maintained their refusal to reassert sovereignty. Subsequently, in 1987, the Portuguese and
Evolution of education systems 
Journal of Educational Administration 38,5

472

Chinese governments agreed that Macau would revert to China in 1999. Like Hong Kong, Macau became a SAR for at least 50 years after the transition. The government was also permitted to retain autonomy in economic, legal and educational matters.

The total land area of Macau is just 24 square kilometers. A population of approximately 470,000 gives a density of 19,600 persons per square kilometer. This far exceeds Hong Kong's 6,500 persons per square kilometer. As in Hong Kong, over 95 per cent of the population is Chinese. Two significant minority groups are a small cadre of Portuguese and a mixed-race group known as the Macanese.

Official figures placed the 1998 GDP per capita at US $\$ 14,500$ (Governo de Macau, 1999a, p. 17). Like Hong Kong, Macau achieved striking economic growth in the 1970s, 1980s and 1990s.

\section{Nature and social origins of educational provision}

Hong Kong: Chinese influence and unified centralized system

Although Hong Kong's education system permits some diversity, the territory does have a dominant entity which is known as the Hong Kong education system (Hong Kong Education Department, 1981, 1999a). As will be explained below, the same cannot be said of Macau. Table I shows figures on the ownership of primary and secondary schools in Hong Kong. Fewer than 10 per cent of institutions are operated by the government; but the aided schools are almost entirely financed and controlled by the government, and are considered part of the public sector. At the primary level, the private sector in Hong Kong operates only 10 per cent of primary schools. At the secondary level, the private sector embraces about one-quarter of the total; but the curricula of these schools and their teachers' conditions of service are guided by the aided and government schools. Thus many of these private schools are still considered part of the Hong Kong education system.

The history of the aided sector dates back to the nineteenth century (Sweeting, 1990). Grants have always been closely linked to controls, and have permitted the government to influence the orientation of the curriculum and the quality of provision. This feature underlay the 1873 Grant-in-Aid for schools

\section{Primary}

Secondary

Table I.

Day-time primary and secondary schools in Hong Kong, 1998

$\begin{array}{lr}\text { Government } & 45 \\ \text { Aided } & 696 \\ \text { Private } & 89 \\ \text { All } & 830 \\ & \\ \text { Government } & 37 \\ \text { Aided } & 352 \\ \text { Private } & 82 \\ \text { All } & 471\end{array}$

Source: Adamson and Li (1999, p. 50) 
and the 1913 Education Ordinance, and has permeated subsequent laws. The Codes of Aid and accompanying Education Regulations are instruments for close control of the aided sector.

The increased government control and the unification and systematization of the centralized education system chiefly arose from the Hong Kong government's desire to counteract influences from mainland China. Especially during the first half of the twentieth century, the dominant external influences were of the Nationalist Party; but during much of the second half of the century the chief focus was on the Communist Party.

From the 1920 s to the 1940 s, the Chinese government, at that time dominated by the Nationalist Party, took steps to limit Communist influence in schools outside as well as inside the country. These steps influenced patterns in Hong Kong. In 1928, the Chinese Ministry of Education asked "Overseas Chinese" schools to register with a specially designated bureau. Details of curriculum and textbooks were required for the registration process (Chan, 1992). Most of the larger schools in Hong Kong decided to register with the Chinese government because their students could only proceed to China for higher studies if the schools were registered. Since registration carried with it an obligation to observe certain regulations, the Chinese authorities were able to exert indirect control over many of the larger schools (Wong Leung, 1969, p. 53). One manifestation was that many schools adopted a $6+3+3$ system to parallel that in mainland China.

The influence of the Chinese government on Chinese-medium schools did not diminish until the late 1940s, when the colonial government, reacting to the growing power of Communism in mainland China, made a determined push to exercise its own control of local education. Amendments to the Education Ordinance 1948 empowered Hong Kong's Director of Education to refuse to register any teacher, deregister a registered teacher, close any school, and control the curricula and textbooks of all schools (Sweeting, 1993, p. 199). In 1949, a Special Bureau was set up to fight Communism in the schools. In 1952, as recommended by the Special Bureau, the first Hong Kong Chinese School Certificate Examination was instituted. At the same time, a Syllabuses and Textbooks Committee sought to provide positive support to schools. More widely, the socio-economic value of English in Hong Kong society became evident, and helped restrict mainland influence through Chinese-medium schools. Table II shows the subsequent decline of Chinese-medium secondary schools in Hong Kong.

\section{Macau: non-interventionist attitude and poly-centered, decentralized systems} Until the late 1980s, the Portuguese colonial government was unwilling to devote significant resources to Macau. Partly because of this, Macau did not develop a dominant and unitary education system. Rather, it had an uncoordinated poly-centered collection of systems which had been imported, with or without adaptation, from Portugal, the People's Republic of China (PRC), Taiwan and Hong Kong. The number of years in the primary, junior
Evolution of education systems

473 
Journal of Educational Administration 38,5

474

secondary and senior secondary cycles varied according to the model. In the mid-1980s, the Portuguese model had a $4+2+3+2+1$ pattern, and the PRC and Taiwan ones were $6+3+3$. The principal model modified from Hong Kong's English-medium system had a $6+5+1$ structure.

One way to simplify classification of Macau's diverse schools is to group them by language of instruction. Some schools operate in Portuguese, others in Chinese, and yet others in English. A fourth category, labeled Luso-Chinese, embraces schools which are run by the government and use Chinese as the main medium of instruction but teach Portuguese as a compulsory subject. Among the Macau schools in 1997/1998, 73.8 per cent operated in Chinese, 13.1 per cent were Luso-Chinese, 8.2 per cent operated in English, and 4.1 per cent operated in Portuguese (Governo de Macau, 1999b, p. 64).

Macau has no aided schools. In 1997/1998, the government sector comprised 17 per cent of the total, while all others were in the private sector. Many schools were operated by religious bodies, social service organizations, commercial enterprises and individuals. The Diocese of Macau was the most important contributor, running 23 per cent of the schools (Table III).

\begin{tabular}{lcc}
\hline & Chinese-medium & English-medium \\
\hline 1960 & 42.1 & 57.9 \\
1965 & 29.0 & 71.0 \\
1970 & 23.3 & 76.7 \\
1975 & 21.3 & 78.7 \\
1980 & 12.3 & 87.7 \\
1985 & 9.5 & 90.5 \\
1990 & 8.3 & 91.7
\end{tabular}

Source: Lee (1997, p. 166)

\begin{tabular}{|c|c|c|c|c|}
\hline Level & Total & Government & $\begin{array}{r}\operatorname{Pr} \\
\text { Diocese of } \\
\text { Macau }\end{array}$ & $\begin{array}{l}\text { Othate } \\
\text { bodies }\end{array}$ \\
\hline Total & 122 & 21 & 28 & 73 \\
\hline Pre-primary & 21 & 8 & 3 & 10 \\
\hline Pre-primary and primary & 34 & 0 & 9 & 25 \\
\hline Pre-primary, primary and secondary & 10 & 0 & 3 & 7 \\
\hline Primary & 20 & 8 & 3 & 9 \\
\hline Primary and secondary & 13 & 1 & 3 & 9 \\
\hline $\begin{array}{l}\text { Primary and secondary technical- } \\
\text { professional }\end{array}$ & 4 & 0 & 1 & 3 \\
\hline Secondary & 18 & 3 & 6 & 9 \\
\hline Technical school & 2 & 1 & 0 & 1 \\
\hline
\end{tabular}

Table III.

Number of schools by type and sponsoring body, Macau, 1997-1998

\section{Percentages of day} pupils in Hong Kong language of instruction 
Macau has a long history of education. The first European-style university in the Far East was established by the Jesuits in Macau in 1594 (Hui and Poon, 1999, p. 104), though was closed in 1762 because of political forces in Europe. In parallel with this Western influence, rich Chinese families operated small schools at home from the early 1800s (Pires, 1991, p. 18). The Portuguese government set up its first official primary and secondary schools in Macau during the 1890s (Governo de Macau, 1994, p. 55). These institutions followed the Portuguese system, with Portuguese teachers adopting Portuguese curricula and textbooks.

Luso-Chinese primary education also commenced at the end of nineteenth century, but the origins were informal and the scale was small. All students in the Luso-Chinese schools were Chinese, and they were taught by Chinese and Portuguese teachers. The schools were intended for poor Chinese, and no fees were charged (Pires, 1991, p. 18).

The Macau government provided education for students studying in official schools, but it did not consider it necessary to support or influence education for most of the local Chinese. As in Hong Kong, before the early twentieth century family schools, private schools and charitable schools were the most common forms of educational organization for local Chinese. This noninterventionist attitude provided room for political influence. Most private schools in Macau supported the Chinese Nationalist movement by introducing civic education and adopting the same curriculum and textbooks. In 1929, physical education was introduced into many Macau schools in accordance with suggestions by the Nationalist government (Chan, 1994).

Hong Kong's model was borrowed as early as 1914 with the establishment of the Macau English College. Most students of this secondary school went to Hong Kong to sit for the University of Hong Kong examination. It was closed 20 years (MCEA, 1966), but other institutions replaced it.

From the early 1910s to the mid 1930s, the government had only a small section within the police force responsible for the licensing of schools. The control was minimal and non-educational. By the early 1930s, as in Hong Kong, most private schools, both Christian and non-Christian, had registered with the Education Department in Guangdong, followed the $6+3+3$ system, adopted the curriculum and textbooks used in China, and presented their senior middle students for university entrance examinations in Guangzhou (Cheung, 1991, p. 116).

As mentioned above, in the late 1940s the Hong Kong government decided to increase its own control of education due to the political tensions in China. The Macau government was faced by similar tensions, but remained apathetic. This resulted in bifurcation of the development of Chinese-medium schools in the two territories.

Until the mid-1960s, the Nationalist forces had the upper hand in the battle to influence Macau schools. Since the Nationalist government had been defeated in mainland China, the principal source of control was from Taiwan.
Evolution of education systems

475 
Journal of Educational Administration 38,5

476
The Church schools were better able to determine their own orientations because they had independent sources of income, but many of these schools were also influenced by Nationalist forces.

The Nationalist dominance was overturned in 1966 by the riots associated with the Cultural Revolution in mainland China. Red-Guard attacks were launched against the Macau government, and the Diocese and pro-Nationalist Catholic schools were besieged by the pro-Communist mass (Leung, 1999). Yet the incident still did not change the Macau government's non-interventionist attitude towards social services and education. Some Catholic leaders moved to Hong Kong, and this allowed the pro-Communist associations to develop further.

\section{Analysis}

Understanding of the social origins of the education systems in Hong Kong and Macau requires comprehension of the combined influence of voluntary efforts, government roles, and competition with external influences. At the very beginning, governments in both territories were reluctant to play a major role in educational provision for local Chinese. The reason has been summarized by $\operatorname{Tam}(1995$, p. 91):

When the two places came under colonial rule, the native population was submissive and the size of intellectual body able to mobilize the mass was almost non-existent. The need to sustain power through knowledge was not urgent. Thus, education, an important institution to spread knowledge, was entrusted to church bodies so as to reduce colonial expenditure.

Before the Second World War, the two colonies displayed similar patterns in educational development. In Hong Kong, although the 1873 Code of Grant-inAid for schools and the 1913 Education Ordinance signified the birth of the socalled local education system, which was to some extent imported from the UK, the multiply-integrated education system envisaged by Archer's model had not yet emerged because of the influences from mainland China on local Chinese education. The third phase of Cycle 1 (see Figure 1) only occurred after the Second World War, and the centralized education system was actualized through different restrictive strategies employed by the colonial government (Sweeting, 1993). In Macau, due to the apathy of the government towards the Nationalist Party's enthusiasm and the later Communist threat, educational provision remained fragmented and uncoordinated. The non-interventionist attitude of the colonial government did not change until the late 1980s. Therefore, in Macau the third phase of Cycle 1 only began in the early 1990s.

\section{Development of educational provision after the 1970s} Hong Kong: improving quality for compulsory fee-free education

In Hong Kong, fee-free education was introduced in government and aided primary schools in 1971. It was extended to junior secondary schooling in 1978, and the following year nine years of schooling were made compulsory. Few countries could boast such an achievement in so short a time. 
Under the new arrangements, no fees were charged in government and aided schools at the primary and junior secondary levels. Private schools charged fees at all levels, but their fees were subject to approval by the Director of Education. Expansion of the public sector during the late 1970s and 1980s was made possible by buying places from private schools in a Bought Place Scheme. In 1980, only 5.9 per cent of junior secondary places were in government schools, while 39.2 per cent were in aided schools, 51.2 per cent were private bought places, and 3.7 per cent were other private places (Hong Kong Education Department, 1981, p. 20).

The fact that large numbers of places in sub-standard private schools had to be bought was controversial. One way to improve quality was replacement of bought-place schools with purpose-built aided schools. By the 1990s, the number of bought places had been much reduced.

Aided schools were heavily influenced by the government. The Codes of Aid set out requirements on such matters as accounts, admission of pupils, and appointment and dismissal of staff. Accompanying Education Regulations set out detailed requirements on such matters as furnishings, safety precautions, class size, toilets, and school holidays.

In order to build quality as well as diversity, the government launched two important innovations in the early 1990s. One was the School Management Initiative (SMI), which was described as a form of decentralization but was widely considered insufficiently flexible to meet the needs of schools (Wong, 1997). In 1997, the Education Commission proposed a more flexible framework for school-based management, and recommended that all schools should have school-based management by 2000 .

The second innovation was the Direct Subsidy Scheme (DSS), launched in 1991 to subsidize private schools which had attained sufficient educational standards. The main objective was "to encourage the growth of a strong private sector as an alternative to public sector education for parental choice" (Hong Kong, Education Department, 1999b). By 1997, 13 private schools had joined the scheme. They received an annual subsidy based on the average per-student cost in aided schools. They also had freedom to set their own curricula, fees and entrance requirements.

\section{Macau: building up the system with compulsory fee-free education}

Portugal's 1974 revolution brought a change of attitude towards overseas territories and a concern to undertake more responsible stewardship. A policy approved in Macau in 1977 provided a framework through which private schools could be supported. Direct subsidies, relaxation of tax burdens and provision of studentships were the main instruments for support; and in 1985 this provision was extended to include subsidy of private school teachers. In the same year, a government Luso-Chinese Secondary School was established; and over the decade public expenditure had increased significantly. In 1975,
Evolution of education systems 
Journal of Educational Administration 38,5

478 education was allocated only 2.2 per cent of the total government budget. By 1983 this proportion had reached 5.3 per cent, though it was still one of the lowest in the world (Bray, 1991, p. 87).

The strongest stimulus to rectify the government's neglect of education came from the 1987 Sino-Portuguese declaration. The government identified education as an important ingredient for stability and transition to the postcolonial era, and the public demanded greater government inputs in order to strengthen local identity (Lai, 1991, p. 64). In 1988, an education reform committee was created, and in 1991, the framework for a Macau educational system was set out in a pair of laws for basic and higher education. The policy for basic education was later supplemented by curriculum organization policies for kindergartens, primary schools and secondary schools.

The year 1995/1996 brought another major step. Approval of a law on free basic education permitted private schools to become members of a scheme to provide seven-year free education for Macau pre-primary and primary students. In 1997/1998 the scheme was expanded to cover ten years; and by 1998/1999, 80 per cent of private institutions had joined the scheme (MCEA, 1999). However, some schools remained outside because they wished to retain control over their admissions, curricula and other domains. Schooling was not made compulsory, though the government envisaged that step in due course.

\section{Analysis}

The unification and systematization of the Hong Kong education system was quite marked during the 1970s and 1980s. Some private schools were supported by the creation of the Bought Place Scheme; but those schools were tightly controlled, and the scheme was ultimately phased out. Also the degree of differentiation and specialization within the aided sector was restricted. The launch of the SMI in 1991 brought some change of heart, and encouraged some diversity within the public sector. The DSS also promoted diversity, though in the first instance few schools were willing to join the scheme because they were reluctant to exchange their stable environments for the potentially turbulent environment of the private sector (Bray, 1995). The government argued that good quality independent private schools could contribute to the differentiation and specialization of the centralized education system, and therefore that their contributions should be recognized and supported. The first and second phases of the centralized system in Cycle 2 of Archer's framework (Figure 1) developed in Hong Kong during this period.

The third phase of Cycle 1 did not commence in Macau until the early 1990s, when the Macau government started to build up a unified education system with fee-free education. By that point in history, the Macau government could not emulate its Hong Kong neighbour and employ restrictive strategies to eliminate the influence of leftist private schools, because they were too well established. The power of the various sponsoring groups forced the Macau government to employ substitutive strategies. The adoption of the substitutive approach was not easy, though was more feasible than the restrictive approach. 
Lack of resources was one challenge. Without government support in the past, most private schools could only survive with small campuses and large classes. In the early 1990s, the average class sizes for private primary and secondary schools were 50 and 45 respectively, and it was not uncommon to have classes with over 60 students (Wong, 1994). If the government had wanted to compete with the private schools by providing better quality education, it would have had either to build many schools of its own or to get control through financial assistance. Neither of these measures would have been easy; and influx of illegal immigrant children during this period made the situation more challenging.

The second challenge facing the Macau government was the place of Portuguese in the curriculum (Yue, 1994). From the government viewpoint, Luso-Chinese schools in which Portuguese was a compulsory subject were a desirable model. However, dominant local sentiment considered that Portuguese should only be an elective because the language does not have strong international status. Thus, in contrast to the English-medium schools in Hong Kong during the 1970s and 1980s, the Luso-Chinese schools in Macau could not easily compete with Chinese-medium schools or even Englishmedium schools. The Macau government had successfully set up the basic legislative and administrative apparatus for the emerging education system, but unification and systematization remained a difficult task.

\section{School leaving examinations and tertiary education}

Hong Kong: centralized systems

Tertiary education has existed in Hong Kong for over a century. A College of Medicine was established in 1887, and incorporated into the University of Hong Kong which was founded in 1911. In 1913, a matriculation examination was introduced for secondary students seeking admission to the university. In 1937, in order to select students for matriculation classes, the Hong Kong Certificate Examination was introduced for Anglo-Chinese secondary students. In 1952, this examination was complemented by the Hong Kong Chinese School Certificate Examination for Chinese-middle students. Two years later, the University of Hong Kong introduced Advanced and Ordinary Level examinations for secondary students, following what was then a dominant model in the UK. In 1963, the Chinese University of Hong Kong was formed as Hong Kong's second university. In contrast to the University of Hong Kong which primarily operated in English, the Chinese University primarily operated in Chinese and aimed particularly to serve graduates from the Chinese-medium schools. The Higher $(\mathrm{H})$ Level examination was established in 1965 to help the Chinese University students from the Chinese-medium schools.

In order to unify the paths for the English-medium and Chinese-medium secondary students, in 1974 the two Ordinary Level examinations were merged to form the Hong Kong Certificate of Education Examination. Examination papers with the same content were set in both Chinese and English. In 1977, the Hong Kong Examinations Authority (HKEA), which is an independent
Evolution of education systems 
Journal of Educational Administration 38,5

480 statutory body, was established. Its main role was to operate the Hong Kong Certificate of Education Examination (HKCEE) and the Hong Kong Advanced Level Examination (HKALE). The HKCEE results are used by schools to select Secondary six students, whereas the HKALE results are used by the tertiary institutions to select their students. All these examinations had a strong effect on the curriculum taught by schools.

A University Grants Committee (UGC), modeled on its counterpart with the same name in the UK, was established in 1965. Its remit was to advise the Hong Kong government on the facilities, development and financial needs of the two universities then existing. Further institutions were established or upgraded in the 1980s, and by the late 1990s eight tertiary institutions were funded by the UGC. This was a further dimension of consolidation and then growth of the unified education system.

\section{Macau: external and internal diversity}

Diversity of the school leaving examinations and university entrance examinations taken by secondary students has been another feature of the Macau poly-centered collection of systems. The Portuguese schools have followed the Portuguese system, and the majority of graduates who have proceeded to tertiary education have gone to Portugal. For the pro-Communist schools, university entrance examination was not a major concern until the late 1970s. Before the success of Macau's economic development, tertiary education was an impossible dream for most of their working class students. However, the extraordinarily gifted students received support from pro-Communist organizations to pursue their tertiary education in mainland China. In 1977, the mainland National Unified College Entrance Examinations were restored after the Cultural Revolution, and the mainland door was opened for Chinese students from Taiwan, Hong Kong and Macau. An informal examination center was set up in Macau for the students of pro-Communist schools. In 1984, this center became an official center for the entrance examination of universities in China. The number of candidates increased steadily during the 1980s and 1990s, and in due course students from all types of schools sat for this examination (Lau, 1993, p. 61).

Schools with links to Taiwan also had arrangements for external examinations. An entrance examination to Taiwanese universities was established in 1954 by the Overseas Chinese Education Committee (Chan, 1992, p. 391). Prior to the 1966 Cultural Revolution riots, candidates could sit examinations in an informal center in Macau; but the subsequent success of the pro-Communist organizations forced the religious schools to sever this link. Macau students therefore had to travel to Hong Kong, where the proCommunist forces were curbed by the Hong Kong government, to sit for the Taiwan examination. Dramatically, the steady improvement of the relationship between the mainland China and Taiwan governments after 1979 paved the path for establishment of a Macau center for the Taiwan examination in 
1993/1994. The Catholic schools took turns to run this examination center, and the number of candidates for this Taiwan examination was comparable to that for the China examination.

Hong Kong's Higher Level examination was another alternative for some Macau secondary students from the mid-1960s until its abolition in 1991. This examination was favoured by one particular Protestant school and several Catholic schools, even though the students had to travel to Hong Kong to sit for the examination.

Some English-medium schools also took UK examinations. The first Macau students sat for the General Certificate of Education (London) examination in 1954 (Macau, 1994, p. 111). However, they had to travel to Hong Kong to do so, and only in 1974 was the first Macau examination center set up. This UK influence, which travelled via Hong Kong, was also evident in commercial subjects. The first Pitman examination center in Macau was set up in 1965, and the first London Chamber of Commerce examination center was established in 1975 (Macau, 1994, p. 96).

This entire dependence on external provision of school leaving examinations and tertiary education was not changed until 1990. A private institution called the University of East Asia had been established in Macau in 1981, and in 1990 operated its first entrance examination for Macau secondary students. The university had been founded primarily to tap excess demand in Hong Kong. In its early years, most students came from Hong Kong; its courses matched the Hong Kong system; and most teaching was in English (Hui and Poon, 1999). However, in 1988 the government bought the main campus of the university from its private owners, and in 1991 it was renamed the University of Macau. By the mid-1990s over 90 per cent of the students came from Macau.

The change of the Macau government's attitude to local tertiary education can also be seen in the figures on the studentships provided for Macau students (Ma, 1999, p. 122). In 1987/1988 only 731 studentships were offered; but the number was increased to 1,623 in 1991/1992, 1,945 in 1993/1994 and 2,287 in 1995/1996. In the early years, support was mainly given to students from government schools; but from the late 1980s students in private schools were also supported. The largest numbers of studentships were for local study. The most popular destinations for external students were mainland China and Taiwan, but support was also provided for study in Portugal, Australia, Canada, Hong Kong and other places.

Finally, Macau's tertiary sector was further strengthened by the establishment of the Macau Polytechnic Institute in 1991. It was based on the College of Continuing Education which had been part of the University of East Asia. The Polytechnic Institute provided diploma and degree courses on travel services, commerce, computer studies, social work, and hotel management.

\section{Analysis}

The early effort of the Hong Kong government to control education through examinations, and the establishment of the UGC in 1965, promoted unification
Evolution of education systems 
Journal of Educational Administration 38,5

482 and systematization as well as expansion of the tertiary sector. Although the number of Hong Kong secondary graduates studying overseas has always been high (Postiglione, 1997), the territory has a long-established and unified tertiary sector. Before 1991, the Chinese University of Hong Kong offered fouryear undergraduate courses rather than the three-year courses offered in all other UGC-funded institutions, and enrolled Form 6 instead of Form 7 graduates through the administration of the Hong Kong Higher Level examination. After considerable debate, the examination was abolished and the Chinese University of Hong Kong moved to a credit unit system in which three years of study was the normal pattern. This showed the scale of both physical and political resources which could be deployed by the Hong Kong government to deal with educational conflicts, in order to unify and systematize the centralized system; and in turn it shows how Hong Kong was moving in Cycle 2 in Archer's model (Figure 1).

The Macau government, in contrast, had only limited substitutive strategies when facing the challenge of the Chinese influence in terms of school leaving examinations and provision of tertiary education. This decentralized pattern will probably continue for the foreseeable future. Specialization and differentiation will still dominate, and will obstruct efforts to unify and systematize. However, the development of local tertiary education in the 1980s and 1990s was of considerable significance.

\section{Conclusion}

This paper has compared the social origins of the education systems in Hong Kong and Macau. The paper argues that the two colonies were very similar in terms of competition between colonial governments and mainland Chinese governments for educational provision to local Chinese before the Second World War. Differences in the ways that the colonial governments reacted to the success of the Communist Party in the early 1950s created a bifurcation for the development of Chinese-medium schools in the two places. The adoption of different restrictive strategies supported by the legislative power of the Hong Kong government and the socio-economic value of English in Hong Kong society reduced the power of Chinese influences in the early 1990s. The degree of unification and systematization was high within the centralized system.

In Macau, the government's non-interventionist attitude caused educational provision to be fragmented and uncoordinated until the late 1980s. The Macau government only started to think seriously about education after the 1987 Sino-Portuguese declaration. The structure of the poly-centered collection of systems together with the power of the sponsoring groups behind each center forced the Macau government to employ substitutive strategies. Even adoption of the substitutive approach was not easy, because of the lack of physical and financial resources, the weak legislative power of the government, and the low socio-economic value of the Portuguese language.

While the Macau government was busy constructing its education system which would most probably be decentralized, the Hong Kong government in 
the early 1990s became more aware of the problems of government dominance and of educational uniformity. In order to permit differentiation and specialization, the SMI and DSS schemes were launched in the early 1990s.

Similar conclusions about the characteristics of the education systems and the strategies adopted by the two governments can be drawn from comparison of school leaving examinations and tertiary education. The Hong Kong government had sufficient physical and political resources to use when dealing with educational conflicts within the centralized system, whereas the Macau government had limited resources when adopting the substitutive strategies to minimize external influences.

In addition to showing the usefulness of comparing Hong Kong and Macau in terms of both development of education systems and their centralization and decentralization processes, this paper demonstrates the possibilities and limitations of Archer's conceptual tools for comparing educational development. First, her socio-historical and comparative approach is found to be valuable even for colonial settings. Second, although the mono-integrated characteristic of educational provision at the beginning of the first cycle predicted by her model did not eventuate in the two colonial systems because educational provisions had always been the concern of churches, colonial officials, and political groups since the early twentieth century, her advice to focus on conflicts among the different interest groups within society has proved valuable. It assists understanding of the substitutive and restrictive strategies adopted by the two colonial governments to eliminate Chinese influences, and their relation with the emergence and elaboration of the respective decentralized and centralized education systems. Third, Archer's identification of four universal characteristics of newly emerged education systems: unification, systematization, differentiation, and specialization together with their variations during the elaboration of the centralized and decentralized education systems provides a useful conceptual tool for comparison of educational development in the two colonial settings.

However, the application of Archer's conceptual tools in the above analysis does have problems. The main difficulty is the identification of the dominant and assertive groups. In Hong Kong, for instance, the government could be considered as the dominant group and the Chinese Nationalists or Communists constituted the assertive groups; but such characterization has already shifted away from the original usage which related to the mono-integrated characteristic of education provision at the beginning of the first cycle and excluded external influences. Therefore, the use of the restrictive and substitutive strategies in relation to the conflicts between the assertive groups and dominant group in this paper is quite different from the original use. Nevertheless, Archer's ideas about the deployment of physical and legislative resources in relation to the restrictive and substitutive strategies help promote understanding of the complexity of conflicts among different ideational and material interest groups during the competition for educational provision within the two colonial settings.

\author{
Evolution of \\ education \\ systems
}

483 
Journal of Educational Administration 38,5

484

\section{References}

Adamson, B. and Li, T. (1999), "Primary and secondary education”, in Bray, M. and Koo, R. (Eds), Education and Society in Hong Kong and Macau: Comparative Perspectives on Continuity and Change, Comparative Education Research Centre, The University of Hong Kong, Hong Kong, pp. 35-57.

Archer, M.S. (1984), Social Origins of Educational Systems, University edition, Sage, London.

Bray, M. (1991), "Planning and financing of education: a comparative perspective", in Wong, H.K. (Ed.), Education Reform in Macau, Centre of Macau Studies, University of East Asia, Macau, pp. 79-95.

Bray, M. (1995), "The quality of education in private schools: historical patterns and the impact of recent policies", in Siu, P.K. and Tam, P.T.K. (Eds), Quality in Education: Insights from Different Perspectives, The Hong Kong Educational Research Association, Hong Kong, pp. 183-98.

Chan, K.W. (1992), Footprints of the Trailblazers: 300 Years of Chinese Education Overseas, in Chinese, Royal Kingsway, Toronto.

Chan, S.W. (1994), "Macau education during the War period: newspaper clippings", Macau Daily News, in Chinese.

Cheung, B.L. (1991), "The relation between school autonomy and government control", in Wong H.K. (Ed.), Education Reform in Macau, in Chinese, Centre of Macau Studies, University of East Asia, Macau.

Government of Hong Kong (1999), Hong Kong 1998, Information Services Department, Hong Kong.

Governo de Macau (1994), Estabelecimentos de Ensino de Macau: Sua Caracterização 1992/93, Direcção dos Serviços de Educação e Juventude, Macau.

Governo de Macau (1999a), Macau em Números, Direcção dos Serviços de Estatística e Censos, Macau.

Governo de Macau (1999b), Inquérito ao Ensino 1997/98, Direcção dos Serviços de Estatística e Censos, Macau.

Hong Kong Education Department (1981), The Hong Kong Education System, Education Department, Hong Kong.

Hong Kong Education Department (1999a), Education in Hong Kong: A Brief Account of the Educational System with Statistical Summary, Education Department, Hong Kong.

Hong Kong Education Department (1999b), Direct Subsidy Scheme, Education Department, Hong Kong, http://www.info.gov.hk/ed/school/dss/dsg_e.htm

Hui, P.K.F. and Poon, H.L.M. (1999), "Higher education, imperialism and colonial transition", in Bray, M. and Koo, R. (Eds), Education and Society in Hong Kong and Macau: Comparative Perspectives on Continuity and Change, Comparative Education Research Centre, The University of Hong Kong, Hong Kong, pp. 99-120.

Lai, Y.M. (1991), "The aims of education reform", in Wong H.K. (Ed.), Education Reform in Macau, in Chinese, Centre of Macau Studies, University of East Asia, Macau.

Lau, S.B. (1993), "The future cooperation between Macau and Guangzhou on education development", Journal of the Macau Society of Social Sciences, in Chinese, Vol. 12, pp. 60-1.

Lee, W.O. (1997), "Social class, language and achievement", in Postiglione, G.A. and Lee, W.O. (Eds), Schooling in Hong Kong: Organization, Teaching and Social Context, Hong Kong University Press, Hong Kong, pp. 155-74.

Leung, B.K.F. (1999), "Church, state and education during the colonial period", in Bray, M. and Koo, R. (Eds), Education and Society in Hong Kong and Macau: Comparative Perspectives 
on Continuity and Change, Comparative Education Research Centre, The University of Hong Kong, Hong Kong, pp. 89-97.

Ma, H.T. (1999), "Education and the labour force", in Bray, M. and Koo, R. (Eds), Education and Society in Hong Kong and Macau: Comparative Perspectives on Continuity and Change, Comparative Education Research Centre, The University of Hong Kong, Hong Kong, pp. 117-31.

MCEA (Macau Chinese Education Association) (1966), Macau Education, Vol. 23, p. 19.

MCEA (Macau Chinese Education Association) (1999), Macau Education, Vol. 5, p. 4.

Pires, B.V. (1991), "Origins and early history of Macau", in Cremer, R.D. (Ed.), Macau: City of Commerce and Culture - Continuity and Change, 2nd ed., API Press, Hong Kong, pp. 7-21.

Postiglione, G.A. (1997), "Schooling and social stratification", in Postiglione, G.A. and Lee, W.O. (Eds), Schooling in Hong Kong: Organization, Teaching and Social Context, Hong Kong University Press, Hong Kong, pp. 137-53.

Sweeting, A. (1990), Education in Hong Kong Pre-1841 to 1941: Fact and Opinion, Hong Kong University Press, Hong Kong.

Sweeting, A. (1993), A Phoenix Transformed: The Reconstruction of Education in Post-war Hong Kong, Oxford University Press, Hong Kong.

Tam, E.T.W. (1995), "A comparative study on the contributions of missionaries to the formative years of colonial education in Hong Kong and Macau", MA dissertation, The University of Hong Kong.

Wong Leung, C.S.N. (1969), "A comparative study of some of the salient features of the curricula of ordinary middle schools in mainland China, Taiwan and Hong Kong between 19491966", MA dissertation, The University of Hong Kong.

Wong, C.S. (1994), "Education", in Ng, C.L. and Wong, H.K. (Eds), Macau: An Overview, in Chinese, Macau Foundation, Macau.

Wong, K.C. (1997), “Organizing and managing schools”, in Postiglione, G.A. and Lee, W.O. (Eds), Schooling in Hong Kong: Organization, Teaching and Social Context, Hong Kong University Press, Hong Kong, pp. 81-94.

Yue, K.L. (1994), "The controversy on language of instruction in Macau", Yazhou Zhoukan, in Chinese, 28 August, pp. 64-5. 